\title{
La vacuna de subunidades recombinantes para herpes zoster demostró ser eficaz en adultos mayores
}

\author{
Adjuvanted herpes zoster subunit vaccine proved to be effective in older adults
}

Hersch J y Col, Lancet 2015 385:1642-52.

\section{Objetivos}

Evaluar la eficacia, inmunogenicidad y seguridad de la vacuna recombinante para herpes zoster ( $\mathrm{HZ} / \mathrm{su})$ en personas de 50 o más años en la prevención de erupción de herpes zoster $(H Z)$.

\section{Diseño, lugar y pacientes}

Estudios fase 3, doble ciego, aleatorizados, vacuna-placebo. Ambos estudios (ZOE-50 y ZOE-70) se desarrollaron en 18 países de Europa, Norteamérica, Sudamérica, Asia y Australia. ZOE-50 incluyó pacientes de 50 años de edad o mayores que no tuvieran historia de $\mathrm{HZ}$, que no estuvieran previamente vacunados para varicela o $\mathrm{HZ}$ y que no presentaran ninguna condición de inmunosupresión. Los pacientes fueron estratificados según su región de origen y según su grupo etario (50 a 59, 60 a 69 y 70 años o más). ZOE-70 sólo incluyó pacientes de 70 años o más.

\section{Intervención}

Se utilizó la vacuna $\mathrm{HZ} / \mathrm{su}$, una vacuna inactiva que contiene subunidades de la glicoproteína $E$ del virus de la varicelazoster y un adyuvante denominado su. Los pacientes fueron asignados en una relación 1:1 a recibir dos dosis de vacuna 0 placebo $(0,5 \mathrm{ml}$ de solución fisiológica), con un intervalo interdosis de dos meses.

\section{Medición de resultados}

ZOE-50 evaluó la eficacia de la vacuna para disminuir el riesgo de $\mathrm{HZ}$, comparado con placebo, en los adultos de 50 años; y si la misma disminuía en los grupos etarios más grandes. Se consideró caso "sospecho" al rash unilateral con dolor sin un diagnóstico alternativo. En esos casos se realizó consulta dentro de las $48 \mathrm{hs}$ tomando fotografías de las lesiones y "confirmando" el diagnóstico con toma de muestras de tres lesiones con técnica de PCR.

ZOE-70 evaluó la eficacia de la vacuna en el grupo etario de pacientes > 70 años y además la eficacia de la vacuna para reducir el riesgo de neuralgia postherpética en los pacientes pertenecientes a este estudio y a los de ZOE-50.

\section{Resultados primarios}

ZOE-50 incluyó un total de 15.41 pacientes, de los cuales 7.698 recibieron al menos una dosis de la vacuna, y 7.713 pacientes recibieron placebo. Durante un periodo promedio de seguimiento de 3,2 años, se confirmaron seis casos de $\mathrm{HZ}$ en el grupo vacunados y 210 casos en el grupo placebo (ver tabla 1).

Los efectos adversos locales y reacciones sistémicas dentro de los siete días postvacunación fueron más frecuentes en el grupo de vacunados. La proporción de participantes que presentó efectos adversos graves o enfermedades potencialmente inmunomediadas o muerte fue similar en ambos grupos.

ZOE-70 incluyó un total 13.900 participantes, de los cuales 6.950 recibieron la vacuna $\mathrm{HZ} / \mathrm{su}$ y 6.950 recibieron placebo. El promedio de edad fue 75,6 años con un seguimiento promedio de 3,7 años, durante los cuales se confirmaron 23 casos de $\mathrm{HZ}$ en el grupo vacunado y 223 casos en el grupo placebo (ver tabla 2).

La eficacia de la vacuna para prevenir neuralgia postherpética fue de $88,8 \%$ (IC95\% 68,7 a 97,$1 ; \mathrm{P}<0,001)$.

La incidencia de efectos adversos serios y muertes fue similar en ambos grupos.

Tabla 1: Tasa de incidencia de herpes zoster por grupo y eficacia de la vacuna en el estudio ZOE-50.

\begin{tabular}{|c|c|c|c|}
\hline & $\begin{array}{l}\text { Vacuna HZ/su } \\
\text { Tasa de incidencia de HZ (n/1000 personas-año) }\end{array}$ & $\begin{array}{c}\text { Placebo } \\
\text { Tasa de incidencia de HZ (n/1000 personas-año) }\end{array}$ & $\begin{array}{l}\text { Eficacia de la vacuna } \\
\qquad \% \text { (IC } 95 \% \text { ) }\end{array}$ \\
\hline Total de participantes & 0,3 & 9,1 & 97,2 (93,7 a 99) \\
\hline \multicolumn{4}{|l|}{ Total por edad } \\
\hline 50 a 59 años & 0,3 & 7,8 & $96,6(89,6$ a 99,3) \\
\hline 60 a 69 años & 0,3 & 10,8 & $97,4(90,1$ a 99,7$)$ \\
\hline 70 años o más & 0,2 & 9,4 & $97,9(87,9$ a 100$)$ \\
\hline
\end{tabular}

Tabla 2: Tasa de incidencia de herpes zoster por grupo y eficacia de la vacuna en el estudio ZOE-70.

\begin{tabular}{|c|c|c|c|}
\hline & $\begin{array}{l}\text { Vacuna HZ/su } \\
\text { Tasa de incidencia de HZ (n/1000 personas-año) }\end{array}$ & $\begin{array}{c}\text { Placebo } \\
\text { Tasa de incidencia de HZ (n/1000 personas-año) }\end{array}$ & $\begin{array}{l}\text { Eficacia de la vacuna } \\
\qquad \% \text { (IC } 95 \%)\end{array}$ \\
\hline Total de participantes & 0,9 & 9,2 & $89,8(84,2$ a 93,7$)$ \\
\hline \multicolumn{4}{|l|}{ Total por edad } \\
\hline 70 a 79 años & 0,3 & 7,8 & $90(83,5$ a 94,4$)$ \\
\hline 80 años o más & 0,3 & 10,8 & $89,1(74,6$ a 96,2$)$ \\
\hline $\begin{array}{l}\text { Subgrupo de participantes de } \\
\text { ambos estudios, } n=16.596\end{array}$ & 0,8 & 9,3 & $91,3(86,8$ a 94,5$)$ \\
\hline
\end{tabular}

\section{Conclusión}

La vacuna $\mathrm{HZ} / \mathrm{su}$ redujo en forma significativa el riesgo de $\mathrm{HZ}$ y de neuralgia post herpética en adultos de 50 años de edad o más. La eficacia en el grupo con >=70 años fue similar a los otros dos grupos etarios.

Fuente de financiamiento: GlaxoSmithKline Biologicals. 


\section{Comentario}

Se estima que el 20 a $35 \%$ de los individuos que han tenido varicela, pueden desarrollar HZ. En Estados Unidos se presentan más de un millón de casos de $\mathrm{HZ}$ por año con una tasa anual de 3 a 4 casos cada 1.000 personas. Suele ser mayor la frecuencia en mujeres. De todos los casos de HZ, hasta el $3 \%$ requerirá hospitalización la cual suele ser más frecuente a mayor edad. En pacientes inmunocomprometidos la incidencia y el impacto de $\mathrm{HZ}$ es mayor, llegando a ser 20 a 100 veces superior a la observada en huéspedes normales ${ }^{1}$.

En la actualidad ya se comercializa una vacuna a virus atenuados contra el $\mathrm{HZ}$ denominada Zostavac. La misma demostró una eficacia del $51,3 \%$ para el control del $\mathrm{HZ}$ y una eficacia del $66,5 \%$ contra la neuralgia postherpética en mayores de 60 $a^{n}{ }^{2}$. Sin embargo, la eficacia disminuye con la edad (siendo de $37,6 \%$ en los mayores de 70 años) y está contraindicada en los pacientes inmunosuprimidos dado que puede causar la enfermedad ${ }^{3}$.
Los estudios que resumimos en este artículo mostraron que la vacuna resultó eficaz para disminuir el riesgo de $\mathrm{HZ}$ en adultos mayores. El estudio ZOE 70, además, incluyó un análisis con un pool de datos de ambos estudios que permitió evaluar el impacto sobre la neuralgia postherpética, lo que no hubiera podido realizarse con los datos de cada estudio individualmente dado su baja frecuencia de ocurrencia.

En ninguno de los estudios se observaron efectos adversos graves asociados a la vacuna.

\section{Conclusiones de los comentadores}

Esta vacuna parece prometedora dado su alta eficacia en estos estudios de fase 3 . También resulta muy importante para la práctica clínica que su eficacia no disminuye en los grupos etarios mayores, que son los que con mayor frecuencia son afectados por el HZ. Se estima que la vacuna HZ/su combinada estará autorizada próximamente para su comercialización en países del primer mundo.

Melina Verna [ Médica de familia. melinaverna @ hotmail.com]

Carolina Carrara [ Servicio de Medicina Familiar y Comunitaria. Hospital Italiano de Buenos Aires. carolina.carrara@ hospitalitaliano.org.ar]

Verna M, Carrara C. La vacuna de subunidades recombinantes para herpes zoster demostró ser eficaz en adultos mayores. Evid Act Pract Ambul. 2016:19(3):77-78. Comentado de: Lal H, y col. Efficacy of an adjuvanted herpes zoster subunit vaccine in older adults. NEJM. 2015;372(22):2087-96. PMID: 25916341, y Cunningham AL, y col. Efficacy of the Herpes Zoster Subunit Vaccine in Adults 70 Years of Age or Older. N Engl J Med 2016;375:1019-32. PMID: 27626517.

\section{Referencia}

1. Vacuna herpes zoster. Comisión de vacunas. Mayo

2015. SADI. https://www.dropbox.com/s/v5ucr7xcqo36t3m/Boletin\%20Vacuna\%20Herpes\%20Zoster\%202015 SADI.pdf?dl=0

2. Oxman MN, y col. A vaccine prevent herpes zoster and postherpetic neuralgia in older adultos. N Engl J med 2005;352:227-84.

3. Johnson RW. Herpes zoster ant postherpetic neuralgia. Expert Rev Vaccines 2010; 9: Suppl 21-6.

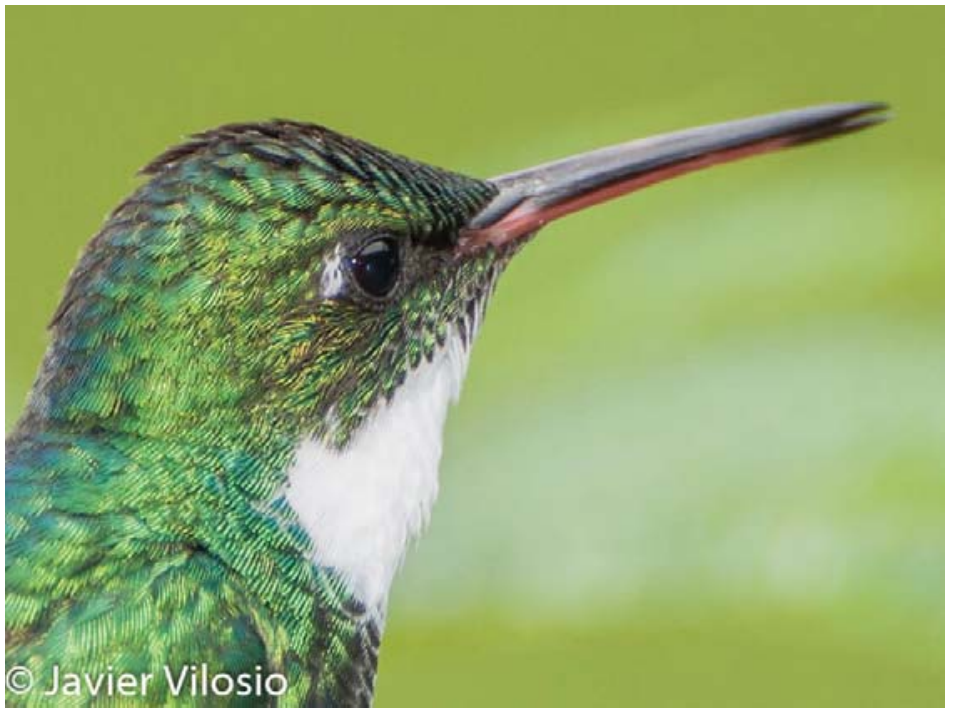

